\title{
Genetically engineered human salivary histatin genes are functional in Candida albicans: development of a new system for studying histatin candidacidal activity
}

\author{
Didi Baev, ${ }^{1}$ Xuewei $\mathrm{Li}^{1}$ and Mira Edgerton ${ }^{1,2}$
}

\begin{abstract}
Author for correspondence: Mira Edgerton. Tel: +1 716829 3067. Fax: +1 7168293942. e-mail: edgerto@buffalo.edu
\end{abstract}

Departments of Oral Biology ${ }^{1}$ and Restorative Dentistry2, School of Dental Medicine, State University of New York at Buffalo Main Street Campus, 3435 Main Street, Buffalo, NY 14214, USA

\begin{abstract}
Histatins are a structurally related family of salivary proteins known as histidine-rich proteins that are produced and secreted by the human major salivary glands. In vitro, histatins are potent cytotoxic proteins with selectivity for pathogenic yeasts including Candida albicans. Studies that investigate the mechanism of action of histatin proteins upon this important human pathogen have used a candidacidal assay in which the histatin is applied extracellularly. In order to develop a model system to study the mechanism of histatin action independently from binding and translocation events, the authors constructed C. albicans strains that contain chromosomally encoded human salivary histatin genes under the control of a regulated promoter. Intracellular expression of either histatin 5 or histatin 3 induced cell killing and ATP release in parallel. Since histatin killing can be initiated solely from intracellular sites, extracellular binding and internalization are preceding transport events. Thus the mechanism of histatin-induced ATP release does not require extracellular binding, and intracellular targets alone can activate ATP release. By employing a codon-optimization strategy it was shown that expression of heterologous sequences in C. albicans can be a useful tool for functional studies.
\end{abstract}

Keywords: histidine-rich proteins, statherin, codon-optimization, RT-PCR

\section{INTRODUCTION}

The yeast Candida albicans is a major pathogen of humans, causing both mucosal and systemic infections, particularly in immunocompromised individuals (Odds, 1988, 1994). This fungus can colonize and infect a wide range of ecological niches in the human body including the gastrointestinal system and superficial mucosal sites of the oral cavity (Odds, 1988). As a non-immune firstline defence system, a large variety of protein molecules such as human neutrophil defensins (Lehrer, 1991) and human salivary histatins (Oppenheim et al., 1988) are targeted against invading micro-organisms in the oral cavity. These proteins have potent microbicidal activity against bacteria and fungi, particularly C. albicans.

Histatins are a structurally related family of neutral to basic histidine-rich proteins that are produced and

Abbreviations: $3^{\prime} U T R, 3^{\prime}$ untranslated region; 5-FOA, 5-fluoroorotic acid; LD-PCR, long-distance PCR; wt, wild-type. secreted by the human parotid and submandibularsublingual glands (Oppenheim et al., 1986, 1988). The major proteins in the family are histatins 1,3 and 5, which consist of 38,32 (51 amino acids with a signal peptide) and 24 amino acid residues, respectively (Oppenheim et al., 1988). Primary sequence data show that histatins 1 and 3 are derived from different structural genes, whereas histatin 5 is a proteolytic product of histatin 3 (Oppenheim et al., 1988). In vitro, they exhibit the ability to kill C. albicans, with histatin 5 being the most active protein of the family (Oppenheim et al., 1986; Xu et al., 1991). Although their precise in vivo role in the human oral cavity has yet to be determined, it is likely that histatins have significant protective effects, as evidenced by microbial overgrowth found in patients with salivary deficiencies.

Many studies have been directed toward understanding the mechanism of action of histatin-specific killing of $C$. albicans. Recently we reported that histatin 5 induced non-lytic release of ATP from C. albicans cells, leading 
to cell death (Koshlukova et al., 1999, 2000). Histatin 5 translocation across the yeast cell membrane followed by targeting to the energized mitochondria has also been implicated in the cytotoxic pathway (Helmerhorst et al., 1999). Thus, histatin activity appears to depend on a multistep process in which extracellular binding, translocation across the yeast cell membrane, intracellular targeting and ATP release may each play a role.

Much of what is known about the fungicidal activity of histatin comes from application of a candidacidal assay in which a cytotoxic protein is applied extracellularly. However, dissection of the requirements of histatin binding and translocation from subsequent intracellular events leading to cell death requires a means of introducing histatin into the cells independently from these initial steps. Intracellular expression of histatin would provide such a mechanism. Therefore, we designed a series of experiments in order to construct genetically engineered codon-optimized C. albicans histatin 3 and histatin 5 genes. The objective was to achieve expression of these genes in C. albicans after stable integration into the genome. We report here the construction of C. albicans strains that contain chromosomally encoded human salivary histatin genes, $C$. albicans codon-optimized human salivary histatin $(\mathrm{CaOSH})$, whose expression is under the control of a regulated promoter. Induction of intracellular expression of histatin 5 and histatin 3 in these cells was found to cause loss of cell viability and efflux of ATP independently from extracellular binding and translocation. These studies show that the cytotoxic activity of histatin can be initiated from the yeast intracellular compartment without participation of extracellular moieties. This system further expands the experimental possibilities of exploring the mechanism by which the histatin molecules or other toxic proteins exert their biological activity upon their targets.

\section{METHODS}

Strains and media. Echerichia coli strain DH5 $\alpha$ (Life Technologies) was used as a host for plasmids and was cultivated in LB medium (Difco). Ampicillin was added at a final concentration of $100 \mu \mathrm{g} \mathrm{ml}^{-1}$. The C. albicans strains used and generated in this work are shown in Table 1. A rich medium, YPD (Difco), was used to grow C. albicans strain SGY-243 for transformation. To grow and characterize the SGY-243 derivatives, we used synthetic YNB medium (BIO 101) plus ammonium sulfate and Complete Supplement Mixture lacking uridine and uracil (BIO 101) $\left(0 \cdot 4 \mathrm{~g} \mathrm{l}^{-1}\right)$ (referred to as YNB-URA), with $2 \%$ glucose or sucrose as carbon source (referred to as YNB-URA + glucose and YNB-URA+ sucrose, respectively). Solid media were prepared by addition of $1.5 \%$ Difco agar.

DNA manipulations. Standard conditions for molecular cloning, hybridization, transformation and electrophoresis were used (Sambrook et al., 1989). Restriction endonucleases and GeneRuler $100 \mathrm{bp}$ DNA Ladder Plus Marker were purchased from Fermentas. T4 DNA Ligase was from Life Technologies. Plasmid DNA was isolated from E. coli by the alkaline lysis method, employing a QIAprep Spin Miniprep Kit from Qiagen. Purification of restriction digest mixes, PCR reaction mixes, and DNA fragment isolation from agarose gels, were done by QIAquick PCR Purification and QIAquick Gel Extraction Kits respectively, both from Qiagen.

Plasmid and gene construction. All oligonucleotides used in this work were made by the CAMBI Nucleic Acid Facility at the University at Buffalo and are summarized in Table 2. The PCR reactions performed in order to amplify the DNA fragments needed to prepare the constructs described below and in Results were carried out in a final volume of $100 \mu \mathrm{l}$, using $1 \mu$ g template C. albicans SGY-243 genomic DNA, and $0.5 \mu \mathrm{M}$ final concentration of each primer (Table 2), in a GeneAmp PCR System 2400 thermal cycler (Perkin-Elmer) using 30 cycles and a Taq PCR Master Mix Kit (Qiagen), unless noted otherwise. Restriction enzyme digest and PCR analyses were employed to monitor all construction steps. In addition, all coding sequences were verified by DNA sequencing.

The E. coli plasmid pUC18 (Yanisch-Perron et al., 1985) was used as a starting vector for construction of the C. albicans integrative plasmids carrying the engineered genes for human salivary histatin 3 , histatin 5 and the human salivary statherin. Plasmid pMalPr was generated by cloning of the CaMAL2 gene promoter (Geber et al., 1992) between the unique Eco0109I and HindIII sites of pUC18. The CaMAL2 promoter region was amplified using the $\mathrm{MalPr}-5^{\prime} / \mathrm{MalPr}-3^{\prime}$ primers as follows: initial denaturation for $3 \mathrm{~min}$ at $94^{\circ} \mathrm{C}$ followed by three-step cycling of $30 \mathrm{~s}$ denaturation at $94^{\circ} \mathrm{C}, 30 \mathrm{~s}$ annealing at $57^{\circ} \mathrm{C}, 30 \mathrm{~s}$ extension at $72^{\circ} \mathrm{C}$ and $5 \mathrm{~min}$ final extension at $72^{\circ} \mathrm{C}$. The $3^{\prime}$ untranslated region (3'UTR) of the gene encoding $C$. albicans elongation factor EF-1 $\beta$ (CaEFB1) (Maneu et al., 1996) was amplified using the same conditions with EFB1/3'U-5' and EFB1/3'U-5' primers. To ensure that the whole $3^{\prime}$ UTR of CaEFB1 was present we amplified a 538 bp DNA fragment instead of the 253 bp fragment described by Maneu et al. (1996). The sequence of the 538 bp

Table 1. C. albicans strains used in this study

\begin{tabular}{|c|c|c|c|c|}
\hline Strain & Genotype & Genes introduced & $\begin{array}{c}\text { Relevant } \\
\text { phenotype }\end{array}$ & Source \\
\hline SGY-243 & ade2/ade2 $\triangle$ ura $3:: A D E 2 / \triangle u r a 3:: A D E 2$ & & $\mathrm{URA}^{-}$ & Kelly et al. (1987) \\
\hline DB6 & SGY-243 RP10::pCaOSH3-RP10 & $\mathrm{CaOSH} 3$ & $\mathrm{URA}^{+}$ & This work \\
\hline DB8 & SGY-243 RP10::pCaHSH3-RP10 & $\mathrm{CaHSH} 3$ & $\mathrm{URA}^{+}$ & This work \\
\hline DB9 & SGY-243 RP10::pCaOSH5-RP10 & $\mathrm{CaOSH} 5$ & $\mathrm{URA}^{+}$ & This work \\
\hline DB10 & SGY-243 RP10:: pCaHSH5-RP10 & $\mathrm{CaHSH} 5$ & $\mathrm{URA}^{+}$ & This work \\
\hline DB13 & SGY-243 RP10::pCaOSS-RP10 & $\mathrm{CaOSS}$ & $\mathrm{URA}^{+}$ & This work \\
\hline
\end{tabular}


Table 2. Synthetic oligonucleotides used in this study

\begin{tabular}{|c|c|c|}
\hline Name & Sequence* & Details $\dagger$ \\
\hline MalPr-5 & TAaggccctTTGATATTTTTGTCTAGTACCATC & GB[M94674] CaMAL2 1-24 \\
\hline MalPr-3' & GCCaagcttTGTAGTTGATTATTAGTTAAACCA & GB[M94674] CaMAL2 516-540" \\
\hline $\mathrm{EFB} 1 / 3^{\prime} \mathrm{U}-5^{\prime}$ & AAGgtcgacGTTTCСТTTCTCСATTTCTATTTT & Contig5-3060 2034-2058 \\
\hline EFB1/3'U-3' & AAGggatccTGCATCTAGTTCTGGGTCCC & Contig5-3060 2552-2572 \\
\hline URA3-5' & AAGggtaccAGTACTAATAGGAATTGATTTGGA & GB[X14198] CaURA3 1-24 \\
\hline URA3-3' & AACgagctcTCTAGAAGGACCACCTTTGATT & GB[X14198] CaURA3 1343-1365 ${ }^{\mathrm{C}}$ \\
\hline $\mathrm{CaOSH}-174 \mathrm{mer} \neq$ & 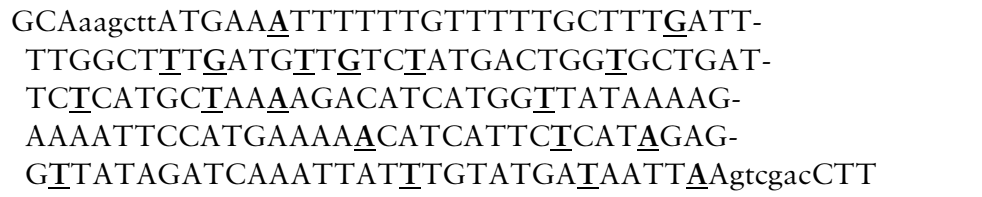 & $\begin{array}{l}\mathrm{Ca} \text { (codon)-optimized human } \\
\text { salivary histatin }(\mathrm{CaOSH}) \\
\text { (with signal peptide) }\end{array}$ \\
\hline $\mathrm{CaOSH}-5^{\prime}$ & GCAaagcttATGAAATTTTTTGTTT & $\mathrm{CaOSH}$ forward primer \\
\hline $\mathrm{CaOSH}-3^{\prime}$ & AAGgtcgacTTAATTATCATACAA & $\mathrm{CaOSH}$ reverse primer \\
\hline $\mathrm{CaOSH} 3-5^{\prime}$ & TAAaagcttATGGATTCTCATGCTAAAAGACATCA & $\mathrm{CaOSH} 3$ forward primer \\
\hline $\mathrm{CaOSH} 5-3^{\prime}$ & AAGgtcgacTTAATAACCTCTATGAGAATGATGTTT & $\mathrm{CaOSH} 5$ reverse primer \\
\hline $\mathrm{HSH}-5^{\prime}$ & GGAaagcttATGAAGTTTTTTGTTTTTGCTTTAAT & wt histatin forward primer \\
\hline HSH-3' & AAGgtcgacTCAATTGTCATACAGATAATTTGAT & wt histatin reverse primer \\
\hline HSH3-5' & TAAaagcttATGGATTCACATGCAAAGAGACATC & wt histatin3 forward primer \\
\hline HSH5-3' & AAGgtcgacTTAATAGCCTCGATGTGAATGATG & wt histatin5 reverse primer \\
\hline CaOSS-153mer $\neq$ & 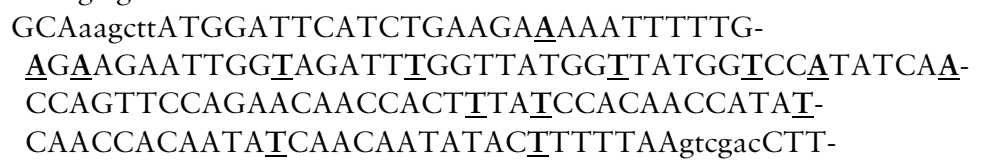 & $\begin{array}{l}\mathrm{Ca} \text { (codon)-optimized human } \\
\text { salivary statherin }(\mathrm{CaOSS}) \\
\text { (without signal peptide) }\end{array}$ \\
\hline CaOSS-5 & GCAaagcttATGGATTCATCTG & $\mathrm{CaOSS}$ forward primer \\
\hline CaOSS-3' & AAGgtcgacTTAAAAAGTATATTG & $\mathrm{CaOSS}$ reverse primer \\
\hline $\mathrm{RP} 10-5^{\prime}$ & AAGggatccCAATTAAACCAATTTTTAAGGCGA & Contig5-3156 587-610 \\
\hline RP10-3' & AAGggtaccTACAACATCTCGTATTCACTTAAT & Contig5-3156 2236-2259C \\
\hline MP-5' & GTGGTTTAACTAATAATCAACTAC & GB[M94674] CaMAL2 515-539 \\
\hline MU-3' & TTATCGATAGCATCTAGTGTATAT & $\begin{array}{l}\text { GB[M94674] CaMAL2 } \\
2255-2278^{\mathrm{C}}\end{array}$ \\
\hline EFU-3' & AAAATAGAAATGGAGAAAGGAAAC & Contig5-3060 2034-2058C \\
\hline EFB1-5 & AGATTTCTCTAAAGTCGAATCTAT & EMBL[X96517] CaEFB1 38-62 \\
\hline EFB1-3' & TACAATTTTTGCATAGCAGCAATA & $\begin{array}{l}\text { EMBL[X96517] CaEFB1 } \\
1009-1033^{\mathrm{C}}\end{array}$ \\
\hline ACT $-5^{\prime}$ & ATATAATCATTCAAAATGGACGGT & $\begin{array}{l}\text { EMBL[X16377] CaACT } \\
\text { 1009-1033 }\end{array}$ \\
\hline ACT-3' & TTAGAAACATTTGTGGTGAACAAT & $\begin{array}{l}\text { EMBL[X16377] CaACT } \\
2788-2812^{\mathrm{C}}\end{array}$ \\
\hline
\end{tabular}

* Restriction sites introduced into primer sequences for cloning purposes are in lower case.

† A supercript $\mathrm{C}$ indicates the complementary strand.

$\ddagger$ The underlined bases in bold indicate the substitutions within the respective wt codons.

fragment bearing CaEFB1 3'UTR was obtained by using the 253 bp 3'UTR as a query against the C. albicans database available at www.ncbi.nlm.nih.gov/BLAST. The sequence of the CaEFB1 gene was found to be represented by fragment 3060 of Contig5 of the C. albicans sequencing project at Stanford University (sequence-www.stanford.edu/group/ candida). The PCR product was cleaved with SalI and BamHI and then cloned into pMalPr, which had already been digested with the same enzymes to yield pMAL/EFB1-3'UTR. Next the C. albicans URA3 (CaURA3) gene was amplified employing URA3-5' /URA3-3' primers. The PCR conditions were identical to those described above except that the extension time was $1 \mathrm{~min}$ and the final extension was carried out for $7 \mathrm{~min}$.
The CaURA3 PCR fragment was then digested with KpnI and SacI, whose recognition sequences had been introduced during the amplification reaction, and cloned into pMAL/EFB13'UTR digested with the same enzymes to yield pMAL/ EFB3'UTR/URA3.

The whole coding sequence of the wild-type (wt) histatin 3 (vanderSpek et al., 1990) was amplified from plasmid pCMVH3, kindly provided by B. O'Connell, as a template, using histatin forward ( $\left.\mathrm{HSH}-5^{\prime}\right)$ and reverse ( $\left.\mathrm{HSH}-3^{\prime}\right)$ primers (Table 2) (O'Connell et al., 1996). The C. albicans codonoptimized human salivary histatin $(\mathrm{CaOSH})$ coding sequence was amplified from $\mathrm{CaOSH}-174 m e r$ synthetic oligo as a template and $\mathrm{CaOSH}$ forward and reverse primers (Table 2) 

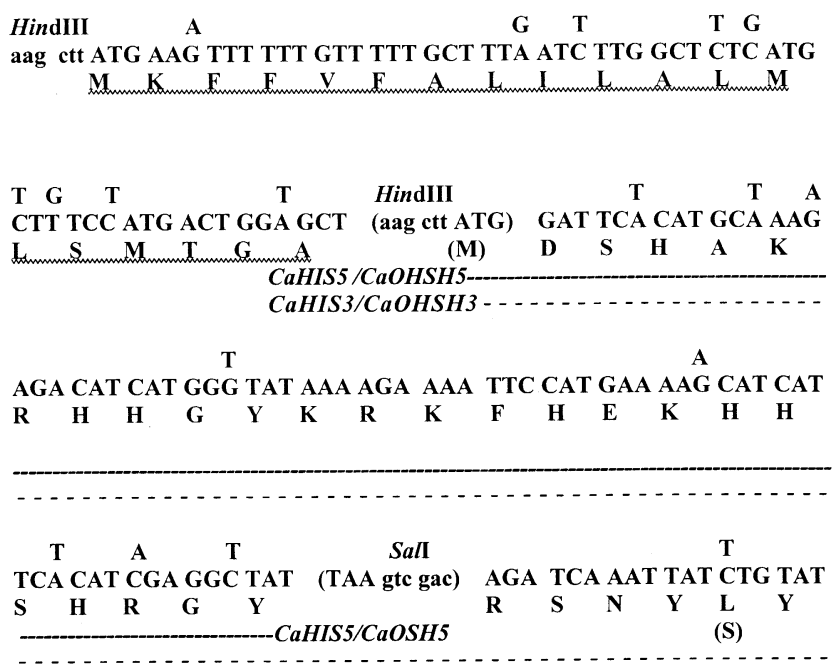

\section{$\begin{array}{llr}\text { T } & \text { A } & \text { SalI }\end{array}$ \\ D $\mathrm{N}$}

Fig. 1. Histatin sequences. The CDNA sequence of the human salivary histatin 3 gene (HIS3) (vanderSpek et al., 1990) is shown with bold capital letters. The amino acid sequence is shown below each codon in the single-letter code. The nucleotides above the HIS3 CDNA indicate the substitutions made in the $C$. albicans codon-biased synthetic sequence (Table 2). The amino acid sequence of the signal peptide is underlined by a wavy line, the sequence of the histatin 5 protein by a heavy dashed line and the sequence of histatin 3 protein by a light dashed line. The beginning and the end of the coding sequences of the codon-optimized genes and the end of the respective wild-type constructs are shown below the amino acid sequence. The introduced translational start and stop codons in the sequences of $\mathrm{CaHSH} / \mathrm{CaOSH} 5$ and $\mathrm{CaHSH} / \mathrm{CaOSH} 3$ (wild-type and optimized histatins respectively) constructs are shown in parentheses. Restriction endonuclease recognition sequences, introduced for cloning purposes, are in lower-case letters.

(Fig. 1). Both forward primers carry HindIII and the reverse primers SalI restriction sites (Table 2). PCR conditions were the same as those used to amplify the CaMAL2 promoter region. The DNA fragments bearing the wt histatin 3 and $\mathrm{CaOSH}$ coding regions were digested with HindIII and SalI and ligated to similarly digested pMAL/EFB3'UTR/URA3 to generate $\mathrm{pCaHSH}$ and $\mathrm{pCaOSH}$.

These constructs were used to generate genes encoding the secreted form of histatin 3. Employing EFB1/3'U-3' reverse primer with $\mathrm{CaOSH} 3-5^{\prime}$ and $\mathrm{HSH} 3-5^{\prime}$ forward primers, respectively, generated PCR fragments consisting of the remaining 32 codons and the EFB1-3'UTR region. Immediately following the HindIII recognition site, the two forward primers also contained a translational start codon (Table 2). PCR reaction conditions were as follows: $94^{\circ} \mathrm{C}$ for $3 \mathrm{~min}$ followed by three-step cycling of $30 \mathrm{~s}$ denaturation at $94^{\circ} \mathrm{C}$, $30 \mathrm{~s}$ annealing at $57^{\circ} \mathrm{C}, 45 \mathrm{~s}$ extension at $72^{\circ} \mathrm{C}$, and $5 \mathrm{~min}$ final extension at $72^{\circ} \mathrm{C}$. After purification the PCR fragments were digested with HindIII and Bam HI and ligated in the same enzyme digested pMAL/EFB3'UTR/URA3 to yield pCaHSH3 and $\mathrm{pCaOSH} 3$.

To construct wt and optimized genes encoding histatin 5, plasmids pHSH3 and pCaOSH3 were digested with SalI and used as templates in LD-PCR employing EFB1/3'U-5' forward primer with either of the reverse HSH5-3' and CaOSH5-3' primers, which, in addition to the SalI recognition site, contained a translational stop signal (Table 2). The amplification conditions were: $94^{\circ} \mathrm{C}$ for 1 min followed by threestep cycling of $30 \mathrm{~s}$ denaturation at $94^{\circ} \mathrm{C}, 15 \mathrm{~s}$ annealing at $60{ }^{\circ} \mathrm{C}, 5 \mathrm{~min}$ extension at $68^{\circ} \mathrm{C}$, and $10 \mathrm{~min}$ final extension at $68^{\circ} \mathrm{C}$ in a final volume of $50 \mu \mathrm{l}$. An Advantage Genomic PCR kit from Clontech Laboratories was used in the amplification reactions. After purification and SalI digestion, the resulting PCR fragments were self-ligated, to yield plasmids pCaHSH5 and $\mathrm{pCaOSH} 5$.

Using CaOSS-153mer as template and CaOSS-5'/CaOSS-3' primers (Table 2), the coding sequence of the secreted version of the human salivary statherin gene (Sabatini et al., 1987) was C. albicans codon-optimized. After amplification $(2 \mathrm{~min}$ at $94{ }^{\circ} \mathrm{C}$ followed by three-step cycling of $30 \mathrm{~s}$ denaturation at $94^{\circ} \mathrm{C}, 15 \mathrm{~s}$ annealing at $57^{\circ} \mathrm{C}, 30 \mathrm{~s}$ extension at $72^{\circ} \mathrm{C}$, and 2 min final extension at $72^{\circ} \mathrm{C}$ ) the resulting PCR fragment was cut with HindIII and SalI and ligated into the abovedescribed pMAL/EFB3'UTR/URA3 to yield pCaOSS.

The sequence of the $1674 \mathrm{bp}$ fragment bearing CaRP10 was amplified from C. albicans SGY-243 genomic DNA with RP10-5'/RP10-3' primers (Table 2), which were designed based on the fragment 3156 of Contig5 of the C. albicans sequencing project at Stanford University (sequencewww.stanford.edu/group/candida), and was obtained by using the GenBank X82017 entry (Swoboda et al., 1995) as a query against the $C$. albicans database. PCR conditions were: initial denaturation for $3 \mathrm{~min}$ at $94^{\circ} \mathrm{C}$, followed by three-step cycling of $30 \mathrm{~s}$ denaturation at $94^{\circ} \mathrm{C}, 30 \mathrm{~s}$ annealing at $57^{\circ} \mathrm{C}$, $1 \mathrm{~min} 30 \mathrm{~s}$ extension at $72^{\circ} \mathrm{C}$, for 30 cycles, and $7 \mathrm{~min}$ final extension at $72^{\circ} \mathrm{C}$. After purification and digestion with $B a m \mathrm{HI}$ and KpnI, the RP10 PCR fragment was ligated to the same enzyme digested pCaOSH, pCaHSH, pCaOSH3, pCaHSH3, pCaOSH5, pCaHSH5 and pCaOSS plasmids to yield pCaOSH-RP10, pCaHSH-RP10, pCaOSH3-RP10, pCaHSH3-RP10, pCaOSH5-RP10, pCaHSH5-RP10 and pCaOSS-RP10, respectively.

Candida transformation. Integrative transformation of $C$. albicans SGY-243 cells with pCaOSH3-RP10, pCaHSH3RP10, pCaOSH5-RP10, pCaHSH5-RP10 and pCaOSS-RP10 was performed using the spheroplast procedure (Kurtz et al., 1986).

Verification of Candida transformants. In order to verify the correct insertion of the plasmids into the CaRP10 locus, PCR amplification analyses were performed using primers MalPr5'/RP10-3' and genomic DNA from transformants as template (Fig. 2). C. albicans genomic DNA was isolated by using DNA Isolation Kit D-6000A from Gentra Systems. PCR reactions were carried out in a final volume of $25 \mu \mathrm{l}$ using $1 \mu \mathrm{g}$ of each genomic DNA, $0.5 \mu \mathrm{M}$ final concentration of each primer, with initial incubation at $94^{\circ} \mathrm{C}$ for $3 \mathrm{~min}$, followed by threestep cycling of $30 \mathrm{~s}$ denaturation at $94^{\circ} \mathrm{C}, 30 \mathrm{~s}$ annealing at $57^{\circ} \mathrm{C}, 2 \mathrm{~min}$ extension at $72^{\circ} \mathrm{C}(30$ cycles $)$, and $10 \mathrm{~min}$ final extension at $72^{\circ} \mathrm{C}$. Additional PCR reactions were performed with the primer combinations EFB1/3'U-5'/RP10-3'; MalPr$5^{\prime} / \mathrm{EFB} 1 / 3^{\prime} \mathrm{U}^{-3} 3^{\prime}$ and $\mathrm{MP}-5^{\prime} / \mathrm{EFU}-3^{\prime}$ in order to verify the integrity of the gene constructs (data not shown). Finally, to ensure that there were no second copies of the respective plasmids integrated ectopically, Southern blot analyses were performed (data not shown).

RNA isolation, cDNA synthesis and RT-PCR. For RNA isolation, C. albicans strains were grown to mid-exponential phase at $37^{\circ} \mathrm{C}$ in $5 \mathrm{ml}$ cultures in YNB-URA, with $2 \%$ 


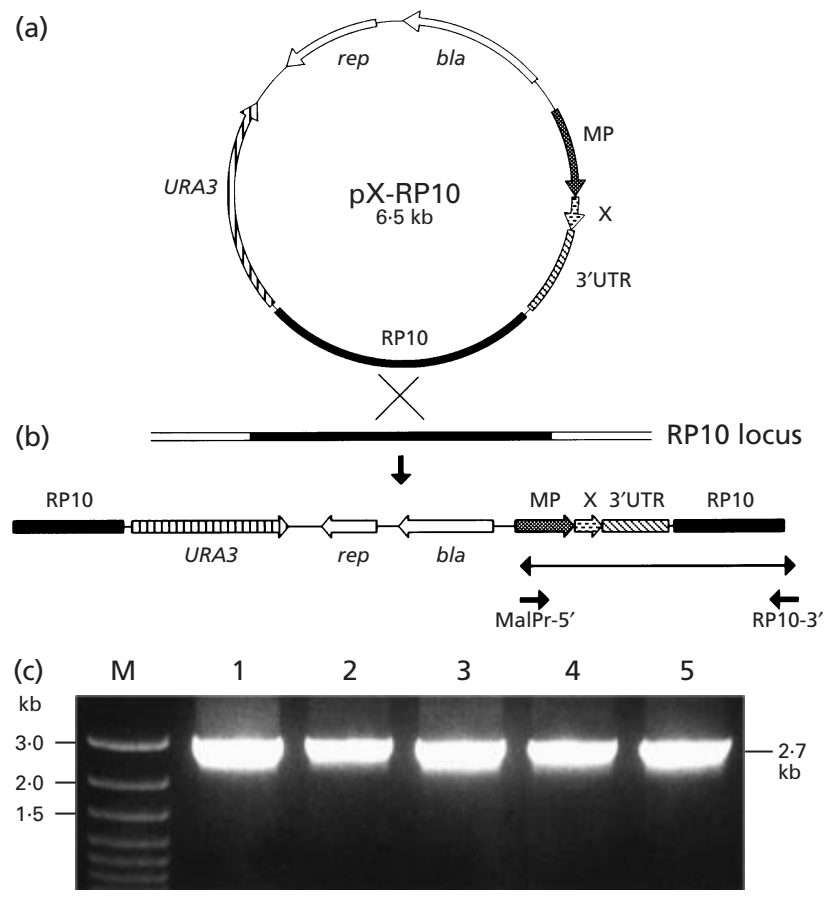

Fig. 2. (a) Diagrammatic representation of the $C$. albicans integration vector ( $\mathrm{XX}-\mathrm{RP} 10)$ constructs, showing the relevant genes. MP represents the CaMAL2 promoter region; $X$ stands for all the coding sequences introduced, and $3^{\prime}$ UTR is the $3^{\prime}$ untranslated region of the CaEFB1 gene. URA3 is the CaURA3 gene. bla and rep are sequences of bacterial origin in the cloning vector pUC18. As described in the text, this vector was designed to express the genetically engineered human salivary histatin 3 and 5 genes upon integration into the $C$. albicans genome (Table 1). (b) Mechanism of integration of pX-RP10based clones into the genome of $C$. albicans. (c) Verification of the integration of the $\mathrm{pX}-\mathrm{RP} 10$ construct into the $C$. albicans $R P 10$ locus by PCR. The location of the MalPr-5'/RP10-3' primers and the actual PCR products obtained $(2.7 \mathrm{~kb})$ are shown below the integration diagram. Lanes $1,2,3,4$ and 5 are the PCR products obtained after analysis of genomic DNA from strains DB6, DB8, DB9, DB10 and DB13 respectively (Table 1). No detectable band was observed upon the same PCR analysis of the genomic DNA isolated from the parental strain SGY-243. M, molecular mass marker.

glucose or sucrose providing the carbon source. Total RNA was prepared using RNeasy Mini Kit from Qiagen, and/or FastRNA Kit-RED from BIO 101. The samples were treated with DNase I using the RNase-Free-DNase Set from Qiagen, and/or the DNA-Free Kit from Ambion. The complete absence of genomic DNA contamination in RT-PCR analysis was controlled by using the following primers for introncontaining genes: EFB1-5' $/$ EFB1-3' for elongation factor gene CaEFB1 (Maneau et al., 1996) and ACT-5'/ACT-3' for the actin-encoding gene CaACT (Losberger \& Ernst, 1989) (Table 2 ). As a routine check we also used the primer combination MP-5' /MU-3' (Table 2), which amplified the coding sequence of the CaMAL2 gene (Geber et al., 1992). MP-5'/EFU-3' (Table 2) primers were used to examine the RNA samples for DNA contamination due to the coding sequences of the newly engineered C. albicans human salivary histatins and statherin genes.

After DNase I treatment, $2 \mu$ g total RNA was used per reaction for the first-strand synthesis (cDNA) using the
RETROscript kit from Ambion. Annealing was performed with the supplied oligo $(\mathrm{dT})_{18}$ primer at $85^{\circ} \mathrm{C}$ for $3 \mathrm{~min}$, and after the reaction mixes were chilled on ice. The cDNA synthesis reactions were made up to a final volume of $20 \mu \mathrm{l}$ and carried out at $43^{\circ} \mathrm{C}$ for $1 \mathrm{~h}$. Then the reverse transcriptase (MMLV-RT) was inactivated by heating the samples for 10 min at $92^{\circ} \mathrm{C}$. cDNA synthesis of the control reaction mix without mMLV-RT was also routinely performed in order to examine for the absence of genomic DNA contamination.

RT-PCR reactions were performed in a final volume of $25 \mu \mathrm{l}$ using a Taq PCR Master Mix Kit (Qiagen). One-microlitre $\mathrm{RT}$ reactions were used as templates. EFB1-5'/EFB1-3' and ACT $-5^{\prime} /$ ACT $-3^{\prime}$ primer combinations (Table 2) were used to amplify the transcripts of the CaEFB1 and CaACT genes respectively, to evaluate the efficiency of the cDNA synthesis as well as the absence of genomic DNA contamination (Fig. 2). The expression of the CaMAL2 gene was monitored by employing MP-5' /MU-3' primers (Table 2), which amplify its coding sequence. The thermal conditions for all three primer combinations were: initial denaturation for $3 \mathrm{~min}$ at $94^{\circ} \mathrm{C}$ followed by 30 rounds of three-step cycling with $30 \mathrm{~s}$ denaturation at $94^{\circ} \mathrm{C}, 30 \mathrm{~s}$ annealing at $57^{\circ} \mathrm{C}, 1 \mathrm{~min} 30 \mathrm{~s}$ extension at $72{ }^{\circ} \mathrm{C}$, and $7 \mathrm{~min}$ final extension at $72^{\circ} \mathrm{C}$. By using MP- $5^{\prime}$ /EFU- $3^{\prime}$ primers (Table 2 ) expression of the newly engineered C. albicans human salivary histatins and statherin genes was studied. PCR conditions were: initial denaturation for $3 \mathrm{~min}$ at $94^{\circ} \mathrm{C}$ followed by 30 cycles of three-step cycling with $15 \mathrm{~s}$ denaturation at $94^{\circ} \mathrm{C}, 15 \mathrm{~s}$ annealing at $57^{\circ} \mathrm{C}, 30 \mathrm{~s}$ extension at $72{ }^{\circ} \mathrm{C}$, followed by $2 \mathrm{~min}$ final extension at $72{ }^{\circ} \mathrm{C}$.

In order to examine the reproducibility of the results and the stability of the transcripts of the genetically engineered genes constructed, total RNA samples were isolated 2, 4, 7, 10, 13, 16 and $23 \mathrm{~h}$ post-induction. All cDNA synthesis/RT-PCR experiments were performed at least three times.

Growth studies and assessment of viability of the constructed C. albicans strains. Single colonies of each of the $C$. albicans strains constructed were inoculated in $5 \mathrm{ml} \mathrm{YNB}-$ $\mathrm{URA}+$ glucose and incubated at $37^{\circ} \mathrm{C}$ for $12-14 \mathrm{~h}$ with constant shaking at 250 r.p.m. Cells $\left(10^{4}\right)$ were then transferred into YNB-URA medium $(3 \mathrm{ml})$ containing $2 \%$ glucose or sucrose. The cultures were grown at $37^{\circ} \mathrm{C}$ with shaking at 250 r.p.m. Growth rate and viability of each cell culture were assessed by a dilution plate assay (Edgerton et al., 1998). At each time point $(1,2,4,7,10,13$ and $23 \mathrm{~h}), 100 \mu \mathrm{l}$ from each culture was removed, serially diluted, and plated on YNBURA agar plates supplemented with glucose or sucrose, depending on the carbon source of the culture medium, to determine the number of viable cells at each time point. The number of surviving cells from sucrose-induced cultures was identical whether plated onto sucrose or glucose solid medium, showing that loss of cell viability had occurred irreversibly during the induction time and could not be rescued following plating on glucose. The percentage growth reduction for each strain cultured in YNB-URA + sucrose was compared with the same strain grown in YNB-URA + glucose as an indication of number of viable cells in culture at each time point, and was calculated as follows: [(cells $\mathrm{ml}^{-1}$ in YNB-URA + glucose - cells $\mathrm{ml}^{-1}$ in YNB-URA + sucrose)/cells ml $\mathrm{ml}^{-1}$ in $\mathrm{YNB}-$ URA + glucose $] \times 100$.

ATP bioluminescence assay. Extracellular ATP levels during the growth of each $C$. albicans strain were measured as described previously (Koshlukova et al., 2000) with the following modifications. The growth conditions for each strain were as described above. Following inoculation into induction media, $100 \mu \mathrm{l}$ from each culture for each strain was 
removed for ATP measurement at 1, 2, 4, 7 and $10 \mathrm{~h}$. Ten hours was the maximum time that extracellular ATP could be assessed in culture before degradation occurred. Cells were pelleted $(5000 \mathrm{~g}, 3 \mathrm{~min})$, and $25 \mu \mathrm{l}$ of the supernatant was placed into $225 \mu \mathrm{l}$ boiling TE buffer $(50 \mathrm{mM}$ Tris, $2 \mathrm{mM}$ EDTA, pH 7.8), boiled for 2 min, then placed on ice for ATP measurement. Extracellular ATP levels were measured by luminometry using an ATP assay kit (Sigma) according to the manufacturer's instructions. A luciferin-luciferase assay mix $(100 \mu \mathrm{l})$ was added to $25 \mu \mathrm{l}$ extracellular material in 96-well black microtitre plates, and light emission was monitored in a 1250 LKB-Wallac luminometer. ATP concentrations of samples were determined from ATP standard curves. Extracellular ATP for each measured time was normalized to pmol ATP per $10^{6}$ cells. ATP release from cells was expressed as fold increase in extracellular ATP from cells grown in sucrose compared with the same strain grown in glucose using the following ratio: pmol ATP per $10^{6}$ cells grown in sucrose/ pmol ATP per $10^{6}$ cells grown in glucose. Cells that had no elevation in ATP release upon induction in sucrose above basal levels of the same strain grown with glucose were scored as 1 -fold release. Each experiment was repeated at least three times and the mean and standard deviation for each strain at the same time point were calculated. Significant differences in extracellular ATP levels between strains were calculated using Student's $t$-test.

\section{RESULTS}

\section{Construction of $C$. albicans strains bearing genetically engineered human salivary histatin and statherin genes}

To generate an integrative expression vector and to achieve inducible expression in $C$. albicans we first cloned the maltose- and/or sucrose-inducible CaMAL2 maltase promoter (Geber et al., 1992) into the E. coli plasmid pUC18 (Yanisch-Perron et al., 1985). The CaMAL2 promoter has recently been reported to be suitable for regulated gene expression in C. albicans (Brown et al., 1996; Cormack et al., 1997; Backen et al., 2000). Next, the promoter region was fused with the 3'UTR of the gene encoding the C. albicans elongation factor, CaEFB1 (Maneau et al., 1996). CaEFB1 was chosen because it is a part of a constitutively expressed gene with abundant transcripts found in all growth phases of C. albicans. Therefore, it was reasonable to expect that transcripts of these constructed genes would be quite stable. In addition, detection of the gene constructs from genomic DNA was simplified because only one copy of the gene consisting of the CaMAL2 promoter region positioned in close proximity to the CaEFB1 3'UTR region would be available. Therefore, detection of the transcripts of these genes was unambiguous upon RT-PCR analysis. As described in Methods, the CaURA3 gene was added to the plasmid construct in order to serve as a selectable marker upon transformation of C. albicans.

Two different sequences encoding the 51 aa residues of the histatin 3 protein with its signal peptide were amplified and cloned between the CaMAL2 promoter and the CaEFB1 3'UTR fragment. The first was the coding sequence of the histatin 3 gene as reported by vanderSpek et al. (1990). The second sequence was codon-optimized for translation in C. albicans (see Methods). The sequences and codon usage for the wildtype and the optimized genes are shown in Fig. 1. For codon-optimized gene sequences, we were guided by a codon usage table of $C$. albicans available at http:// www.kazusa.or.jp/codon/. The genes consisting of the CaMAL2 promoter region, wild-type histatin or $C$. albicans optimized human salivary histatin coding regions followed by the CaEFB1 3'UTR were designated $\mathrm{CaHSH}$ and $\mathrm{CaOSH}$ respectively. These constructs were used to generate derivatives of the wild-type and optimized sequences that lack the first 19 codons encoding the signal peptide, in order to produce genes encoding the secreted form of histatin 3. The wild-type and optimized genes constructed were designated $\mathrm{CaHSH} 3$ and $\mathrm{CaOSH} 3$ respectively. These two gene constructs were used to engineer separate genes encoding the sequence of histatin 5 that is found in saliva as a proteolytic product of histatin 3 . These genes were designated as CaHSH5, having the wild-type coding sequence; and $\mathrm{CaOSH}$, bearing the C. albicans codonoptimized sequence (Fig. 1).

As a control in assessment of the viability of the strains expressing engineered histatin genes upon induction, we also constructed a $C$. albicans codon-optimized human salivary statherin gene $(\mathrm{CaOSS})$ based on the cDNA sequence reported by Sabatini et al. (1987). Statherin is a salivary protein that is similar in size to histatin 3 but does not exhibit candidacidal activity (unpublished results).

The final plasmid construction step was amplification and cloning of a target region into the vectors carrying the above-described genes to ensure stable integration into the genome of the recipient C. albicans SGY-243 cells following transformation. The CaRP10 locus was chosen to serve this purpose (Swoboda et al., 1995; Care et al., 1999; Backen et al., 2000). We chose SGY-243 as the recipient strain since it has a very similar profile of histatin sensitivity as the clinical isolate (DS1) we have previously studied (Edgerton et al., 1998).

Plasmid pX-RP10, which represents all constructs used to transform C. albicans strain SGY-243, is shown in Fig. 2(a). The SGY-243 derivative strains and the genetically engineered $C$. albicans genes are summarized in Table 1. After transformation, the correct integration into one of the two alleles of the CaRP10 gene was confirmed by PCR analysis of isolated genomic DNA. The mechanism of integration and the location of the MalPr-5'/RP10-3' primers are shown in Fig. 2(b), and Fig. $2(\mathrm{c})$ indicates the PCR products obtained.

\section{Inducible expression of the genetically engineered human salivary histatin and statherin genes}

To study the expression of the integrated $\mathrm{CaOSH}$, $\mathrm{CaHSH}$, CaOSH5, CaHSH5 and CaOSS genes in the respective DB6, DB8, DB9, DB10 and DB13 strains (Table 1), we employed RT-PCR analysis. To ensure that no genomic DNA contamination interfered with the analysis, all total RNA samples were treated with 

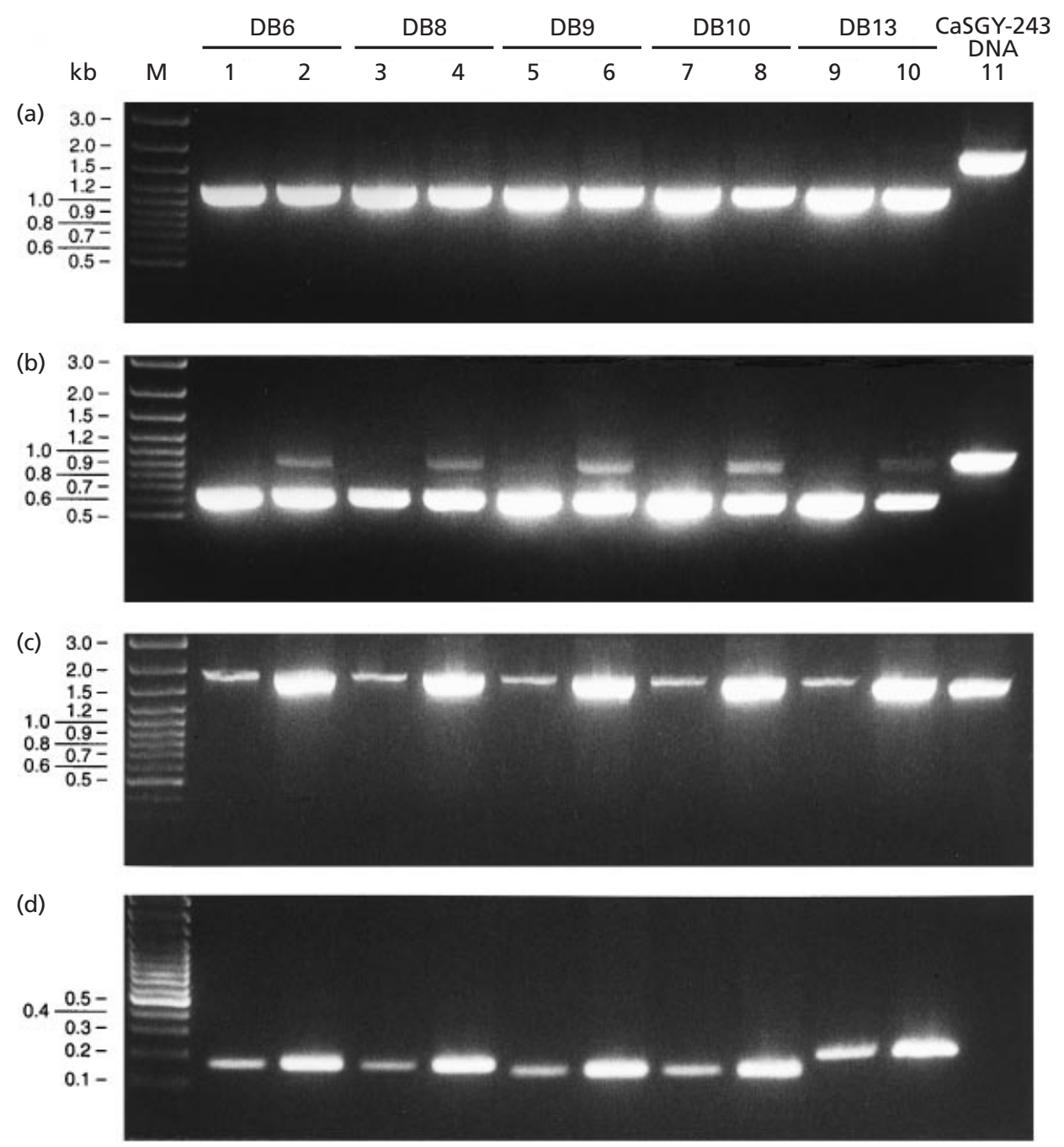

Fig. 3. Analysis of RT-PCR products of total RNA samples. Odd lane numbers 1-9 represent RNA samples obtained from cultures grown on YNB-URA+glucose; even lane numbers 2-10 represent samples from those grown on YNB-URA + sucrose (inducing conditions). Lane 11 represents the respective fragments obtained after C. albicans SGY-243 genomic DNA PCR. M, molecular mass marker. The following combinations of primers (Table 2) were employed: (a) ACT5'/ACT-3', which amplify CaACT. (b) EFB1-5'/EFB1-3', which amplify CaEFB1. (c) MP-5'/MU-3', which amplify CaMAL2. (d) MP-5'/EFU-3', which amplify the sequences of the newly engineered genes CaOSH3 (strain DB6, lanes 1 and 2), CaHSH3 (strain DB8, lanes 3 and 4), CaOSH5 (strain DB9, lanes 5 and 6), CaHSH5 (DB10, lanes 7 and 10) and CaOSS (strain DB13, lanes 9 and 10).

DNase I and analysed by PCR prior to first-strand DNA synthesis (cDNA) and RT-PCR reactions. The complete absence of genomic DNA in the samples was monitored by using primers that amplify intron-containing genes. We chose the housekeeping genes encoding elongation factor EFB1 (Maneu et al., 1996) and actin (Losberger \& Ernst, 1989) as previously reported by Schaller et al. (1998). Amplification of the mRNA of these two genes served to evaluate the sensitivity and efficiency of the RT-PCR reactions in addition to serving as genomic DNA contamination controls. Both proved to be well suited as internal controls since a high level of transcript was detected easily in all samples (Fig. 3a, b). A weak band was evident in all total RNA samples isolated from cells grown on sucrose-containing medium in addition to the strong band corresponding to the EFB1 messenger (Fig. 3b). This additional band corresponds to the nonspliced EFB1 mRNA and it is not due to genomic DNA contamination. We did not investigate the reason for this observation.

We also monitored total RNA samples for genomic DNA contamination due to the sequences of the CaMAL2 and the engineered C. albicans human salivary histatin and statherin genes. The same primers were used to monitor RNA samples for DNA content as well as for RT-PCR analysis of their expression. It was necessary to ensure no such DNA sequences could be detected by direct RNA PCR analysis, to allow unambiguous detection of transcripts of the maltase gene 
as well as the engineered C. albicans human salivary histatin and statherin genes (Fig. 3c, d).

Although previous work has demonstrated that CaMAL2 mRNA is undetectable by Northern blot analysis when C. albicans was grown on glucose (Geber et al., 1992), we found CaMAL2 mRNA was easily detectable in RNA samples of strains grown in glucosecontaining medium using RT-PCR (Fig. 3c). However, this is not surprising since RT-PCR has been shown to be thousands of times more sensitive than the traditional RNA blot methods (Wang et al., 1989).

The results of the RT-PCR analysis of the expression of engineered $\mathrm{CaOSH}$, CaHSH3, $\mathrm{CaOSH}$, CaHSH5 and CaOSS genes are shown in Fig. 3(d). Based on the above results, it was not surprising to detect their mRNA in RNA samples from glucose-grown cells. As expected, positive correlation with the expression of the CaMAL2 was observed (Fig. 3c, d). Transcripts of the engineered genes were easily identified in all RNA samples examined, showing that these genes were transcribed and the respective transcripts were stable. Moreover, all transcripts of these genes were polyadenylated as indicated by the use of oligo(dT) primer for cDNA synthesis.

To examine the reproducibility of the results presented in Fig. 3, total RNA samples were prepared from the strains generated in this work (Table 1) that were grown on YNB-URA + glucose and YNB-URA + sucrose at different times after induction. Similar patterns of gene expression were obtained following RT-PCR analysis, indicating that the results were highly reproducible.

\section{Induction of human salivary histatin genes in C. albicans cells results in loss of cell viability}

To determine whether histatin that is localized intracellularly is capable of causing cell death without contribution from extracellular components, dilution plate assay experiments were performed to measure loss of cell viability upon induced expression of the $\mathrm{CaOSH} 3$, $\mathrm{CaHSH}$, $\mathrm{CaOSH}$, CaHSH5 and CaOSS genes. Unlike previous in vitro assays of histatin toxicity, C. albicans cells were induced to express these proteins in sucrosecontaining growth medium and the toxicity of tested proteins was assayed while cells were continuously incubated in this medium. YNB medium contains divalent cations at concentrations that inactivate histatins if they are applied extracellularly in this environment (Xu et al., 1999). Therefore, any expressed histatin that may become externalized as a result of possible cell lysis will not have toxic activity in this growth medium environment. This permits assessment of the intracellular cytotoxic effects of the histatins independently from extracellular binding and uptake steps.

All strains showed identical growth kinetics and exhibited no reduction in cell viability on glucose-containing medium compared to the control strain DB13 (data not shown). Induction of non-codon-optimized strains DB8 (CaHSH3) and DB10 (CaHSH5) showed no

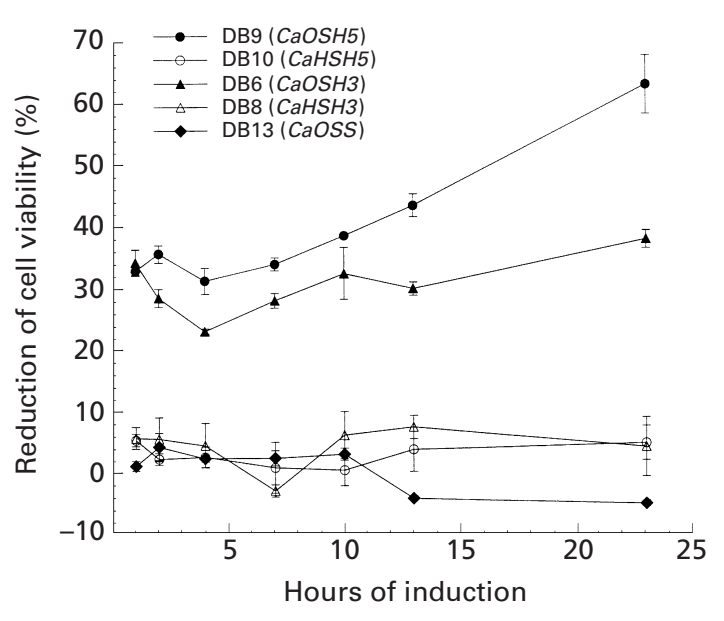

Fig. 4. Effects of the induction of the CaOSH3, CaHSH3, $\mathrm{CaOSH} 5, \mathrm{CaHSH} 5$ and $\mathrm{CaOSS}$ genes on reduction of cell viability upon growth in YNB-URA + sucrose medium. The percentage growth reduction for each strain cultured in YNB-URA+ sucrose was compared with the same strain grown in YNB-URA + glucose as an indication of number of viable cells in culture at each time point, and was calculated as follows: [(cells $\mathrm{ml}^{-1}$ in YNB-URA+glucose-cells $\mathrm{ml}^{-1}$ in YNB-URA+ sucrose)/cells ml ${ }^{-1}$ in YNB-URA + glucose] $\times 100$. Each value represents mean data from three independent experiments performed with each strain; the bars represent SD.

significant loss of cell viability in comparison to strain DB13 on sucrose-containing medium (Fig. 4). The detection of the transcripts of the $\mathrm{CaOSH} 3$ and $\mathrm{CaOSH} 5$ genes on glucose did not result in a functional phenotype that caused cell killing since expression from the CaMAL2 promoter in the presence of glucose was insufficient to support the function of the $\mathrm{CaOSH} 3$ and $\mathrm{CaOSH} 5$ genes. However, significant reduction of the viability of strains DB6 and DB9, which express the $\mathrm{CaOSH} 3$ and $\mathrm{CaOSH} 5$ genes, respectively, was found following induction in sucrose, showing that histatins are capable of cytotoxic activity exclusively within the intracellular compartment (Fig. 4). Within $2 \mathrm{~h}$ of inoculation in sucrose-containing medium, the viability of strains DB6 and DB9 was reduced by $28 \cdot 5 \pm 1 \cdot 5 \%$ and $35.6 \pm 1.4 \%$ respectively (means \pm SD). Viability of strain DB9 was reduced by $62 \cdot 8 \pm 4 \cdot 7 \%$ and that of strain DB6 was reduced by $37 \cdot 7 \pm 1 \cdot 4 \%$ after $23 \mathrm{~h}$ of induction. Light microscopic examination of induced DB6 and DB9 cells showed no evidence of cell lysis at any time up to $24 \mathrm{~h}$ of induction, consistent with the previously observed non-lytic mechanism of histatininduced cytotoxicity.

Strain DB9, which expresses $\mathrm{CaOSH5}$, showed more reduction in cell viability over the entire incubation time course under inducing conditions compared to strain DB6, which expresses $\mathrm{CaOSH} 3$ (Fig. 4). These results match previously reported findings that the candidacidal activity of extracellularly applied histatin 5 is higher than that of histatin 3 (Oppenheim et al., 1986; Xu et al., 1991). In addition, the present studies show that the higher fungicidal activity of histatin 5 compared with histatin 3 may not be due to increased cell binding or 


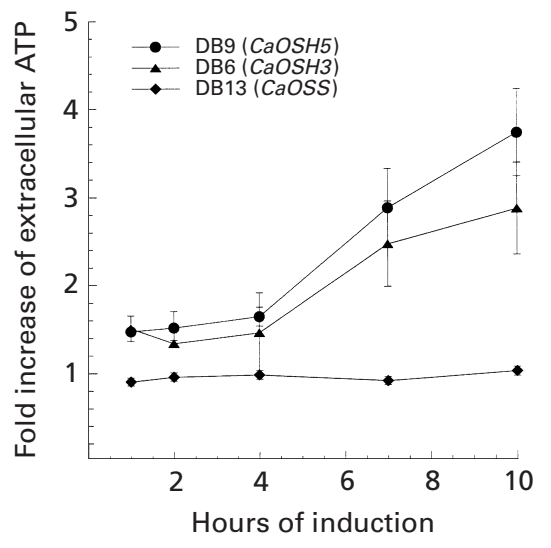

Fig. 5. Effects of the induction of the CaOSH3, CaOSH5 and CaOSS genes on extracellular release of ATP following induction in YNB-URA + sucrose medium. Extracellular ATP for each measured time was normalized to pmol ATP per $10^{6}$ cells. ATP release from cells was expressed as fold-increase in extracellular ATP from cells grown in sucrose compared with the same strain grown in glucose using the following ratio: pmol ATP per $10^{6}$ cells grown in sucrose/pmol ATP per $10^{6}$ cells grown in glucose. Cells that had no elevation in ATP release upon induction in sucrose above basal levels of the same strain grown in glucose were scored as 1-fold release. Each value represents mean data from three independent experiments performed with each strain; the bars represent SD.

uptake but rather is a result of greater intracellular cytotoxic activity of histatin 5 .

\section{Induction of human salivary histatin genes in the cytosolic compartment of C. albicans cells induces release of cellular ATP independently from extracellular binding of histatin}

We have found that fungicidal activity of histatin 5 is initiated by a rapid release of intracellular ATP via a non-lytic mechanism (Koshlukova et al., 1999). The known mechanisms of specific ATP release include facilitated transport down a favourable concentration gradient or conductive transport through an ATPspecific or other ion channels. To determine whether histatin is capable of initiating this release of ATP exclusively from the cytosol or if extracellular binding coupled with some signal pathway is involved in this process, we utilized our model of intracellularly induced histatin expression to measure ATP release. ATP in the culture supernatant was measured at $1,2,4,7$ and $10 \mathrm{~h}$ following induced expression of the $\mathrm{CaOSH}$, $\mathrm{CaHSH} 3$, $\mathrm{CaOSH}$, CaHSH5 or CaOSS gene. No rise in extracellular ATP levels above constitutive baseline levels was found in culture supernatants from the non-codonoptimized strains DB8 (CaHSH3) and DB10 (CaHSH5) nor in strain DB13 expressing salivary statherin in sucrose-containing medium (data not shown). However, extracellular ATP levels were elevated $1 \cdot 5$-fold $1 \mathrm{~h}$ postinduction in strains DB6 and DB9, which express the $\mathrm{CaOSH} 3$ and $\mathrm{CaOSH} 5$ genes, compared to non-inducing conditions for each strain (Fig. 5). Student's $t$-test showed that levels of extracellular ATP were significantly higher $(P<0.05)$ for both DB6 and DB9 compared with strain DB13 at all time points tested. Extracellular ATP levels remained constant for both strains DB6 and DB9 over the first $4 \mathrm{~h}$ post-induction, then rose to $2 \cdot 5 \pm 0 \cdot 4$ - and $2 \cdot 9 \pm 0 \cdot 4$-fold respectively at $7 \mathrm{~h}$ and $2 \cdot 8 \pm 0 \cdot 5$ - and $3 \cdot 7 \pm 0 \cdot 5$-fold respectively at $10 \mathrm{~h}$ post-induction. Although ATP levels in the extracellular medium following induction of strain DB9 were consistently found to be higher than those seen for strain DB6, the high variability in these measurements did not permit these differences to become statistically significant until $10 \mathrm{~h}$ post-induction. However, strain DB9, which expresses $\mathrm{CaOSH} 5$, showed more ATP release over the entire incubation time course under inducing conditions compared to strain DB6, which expresses $\mathrm{CaOSH} 3$ (Fig. 5). These results show that expression of both histatin 5 and histatin 3 causes release of ATP from cells prior to $1 \mathrm{~h}$ of induction of histatin proteins. This efflux of ATP occurs from cells that are exposed to histatin solely intracellularly, showing that extracellular binding components are not required for ATP release.

\section{DISCUSSION}

Histatin killing of C. albicans is known to involve three distinct steps: initial binding of the protein with specific cell-envelope components, translocation of protein across the cell membrane with intracellular accumulation, and selective efflux of ATP and other ions extracellularly. It is not known whether histatin binding alone is sufficient for cell killing or if binding and internalization are precursor steps for transport of histatin to its target intracellular sites. To clearly differentiate between these steps in the mechanism of histatin killing, we constructed C. albicans strains capable of expression of the human salivary histatin 3 and 5 genes.

Our findings that intracellular expression of either histatin 5 or histatin 3 induces cell killing and ATP release provide strong evidence that histatin killing is initiated from an intracellular site and that extracellular binding and internalization are transport events. These findings confirm studies by Xu et al. (1999) that found elevated extracellular salt concentration and decreased temperature lowered histatin binding and uptake and reduced cell killing. Our system also suggests a reason for inhibition of histatin candidacidal activity in high salt conditions. Induction of intracellular expression of histatins in the present system was carried out in highsalt growth medium and we found both killing of and ATP release from these cells. These data suggest that the inhibition of killing found in high-salt medium in the candidacidal assay using exogenously applied histatin is due primarily to decreased initial extracellular binding and/or translocation of histatin.

Intracellular induction of histatin proteins also provides a method of direct comparison of cytotoxic activities of proteins independently from their ability to bind and be transported by C. albicans cells. Histatin 5 and histatin 
3 differ in structure only that histatin 3 contains eight additional amino acids at the C-terminus. It is not known whether these additional amino acids confer any functional advantage upon the molecule in binding or intracellular uptake. Our data comparing ATP release and cell death following intracellular expression of these two molecules found that cells with induced expression of histatin 5 showed greater cytotoxic effects than those with expressed histatin 3 , similar to results with exogenous addition of these proteins in a candidacidal assay (Edgerton et al., 1998). Although relative levels of protein expression were not quantitated between these two cell lines, these results may reflect higher intracellular cytotoxic effects of histatin 5 compared with histatin 3.

ATP release was detected within $1 \mathrm{~h}$ after intracellular induction of histatin 5 or histatin 3 , and extracellular concentrations of ATP closely paralleled levels of cell killing. These results show (1) that the mechanism of histatin-induced ATP release does not require extracellular binding for ATP efflux and (2) that intracellular targets alone can activate ATP release. These targets may be the cytosolic portion of a yeast membrane channel capable of transport of ATP and/or other ions. Recently, it was shown that K1 killer toxin acts on sensitive yeast cells by activating potassium efflux via a plasma membrane ion channel of Saccharomyces cerevisiae (Ahmed et al., 1999). Histatin killing may involve activation of C. albicans membrane channels that induce efflux of ATP as well as potassium.

Naturally occurring histatin 5 is a proteolytic product of histatin 3, which is translated with a signal peptide that is cleaved upon secretion (Oppenheim et al., 1988). Therefore, we engineered separate $C$. albicans genes encoding histatin 3 and histatin 5 proteins by employing four different coding sequences. Two wild-type sequences for $\mathrm{CaHSH} 3$ and $\mathrm{CaHSH}$, and two codonoptimized sequences for $\mathrm{CaOSH} 3$ and $\mathrm{CaOSH} 5$ in which all codons are optimal for translation in C. albicans, were constructed. The initial synthetic coding strand used to engineer the $\mathrm{CaOSH} 3$ and $\mathrm{CaOSH} 5$ genes contained the sequence information for the full length of the histatin 3 protein (Fig. 1, Table 1).

A codon-optimization strategy was employed because expression of heterologous genes in C. albicans is often compromised owing to non-canonical decoding of the CUG codon as serine instead of leucine (Santos et al., 1995; Cormack et al., 1997; Morschhauser et al., 1998). Another factor to be considered is that the codon bias within a heterologous ORF may influence the rate of translation due to a non-optimal ratio between the codons being translated and the abundance of isoacceptor tRNAs. These factors may affect the translational efficiency of mRNA of a heterologous ORF compared with its codon-optimized version. Hence, the stability of a non-optimized versus optimized mRNA may depend on the interplay between the rate of mRNA translation and degradation (Beelman \& Parker, 1995; Ross, 1995). Additionally a non-optimal rate of trans- lation may affect the stability of the protein product being synthesized.

All our genetically engineered genes (Table 1) were transcribed and gave rise to stable transcripts. As expected, all showed positive correlation with the transcription of the CaMAL2 gene (Fig. 3c, d). We were not able to detect any differences in the abundance and stability of the transcripts of the genes bearing optimized versus non-optimized coding sequences, suggesting that codon-optimization was not important for transcription of these engineered genes. It is possible, however, that transcription of longer non-optimized sequences or sequences with greater differences in codon usage may be attentuated at the level of transcription. Recently, Te'o et al. (2000) attributed the unsuccessful attempts of expression of the Dictyoglomus thermophilum xynB gene in the filamentous fungus Trichoderma reesei to be due to excessive codon usage differences affecting the transcription of the heterologous gene.

In the present study, only the strains expressing the codon-optimized $\mathrm{CaOSH} 3$ and $\mathrm{CaOSH} 5$ genes showed significant reduction in cell viability upon induction (Fig. 4). This result can be explained if we assume that the transcripts of the non-optimized genes were poorly translated due to non-optimal ratios of the array of codons expressed and the availability of relevant isoacceptor tRNA species in the host. It is well known that the choice of synonymous codons in many organisms is strongly biased and a positive correlation exists between high gene expression and use of particular codons in a given organism (Holm, 1986). The wt sequence of histatin 3 contains one CUG codon, which encodes L48 in the full-length (51 aa) and L29 in the secreted form (32 aa) of the histatin 3 protein (Fig. 1). However, histatin 5 (24 aa) has no amino-acid residues that are encoded by the CUG codon. Therefore we speculate that the complication of expressing heterologous gene coding sequences in C. albicans is likely to be due in part to the strong codon bias preference rather than only to the non-standard translation of the CUG codon (Santos et al., 1995).

Histatin proteins lack antigenic properties, most likely as a result of their low molecular mass and flexible secondary structure, and to date no suitable anti-histatin antibodies are available for immunoblot experiments. Therefore, it was not possible to study the efficiency of translation of the optimized versus non-optimized transcripts of the gene constructs directly. However, positive correlation is evident in the reduction of cell viability upon induction of $\mathrm{CaOSH} 3$ and $\mathrm{CaOSH} 5$ genes (Fig. 4) with the candidacidal experiments reported earlier (Koshlukova et al., 1999, 2000). Moreover, during the course of the cell viability studies positive correlation between ATP release and cell viability reduction of strains DB6 and DB9 was observed (Fig. 5).

As shown in Fig. 3(c), CaMAL2 mRNA was detected upon RT-PCR analysis of RNA samples derived from cells grown on glucose. However, the strains carrying 
$\mathrm{CaOSH} 3$ and $\mathrm{CaOSH} 5$ genes did not show any growth reduction in glucose in comparison to the cells bearing the CaOSS gene, nor compared to the same strains grown in sucrose. Therefore, the detection of the transcripts of the $\mathrm{CaOSH} 3$ and $\mathrm{CaOSH} 5$ genes on glucose did not correlate with the functional phenotypes caused upon induction when cells were cultured on medium containing sucrose. The expression from the CaMAL2 promoter in the presence of glucose is obviously insufficient to support the function of the $\mathrm{CaOSH} 3$ and $\mathrm{CaOSH} 5$ genes. In this respect our data are in line with the findings of Backen et al. (2000), who reported that basal levels of expression from the CaMAL2 promoter in the presence of glucose were not enough to support an essential (CaURA3) gene function based on two criteria: (1) failure to complement the ura3 mutation and (2) failure to confer 5-FOA sensitivity. Therefore, the activity of the CaMAL2 promoter on glucose was not sufficient to permit functionally significant levels of gene expression. Similarly, Cormack et al. (1997) demonstrated that expression of the reporter yEGFP3 green fluorescent protein gene in C. albicans under the CaMAL2 promoter was significant only upon induction, and no fluorescence was seen during glucose growth. With our demonstration of using the CaMAL2 promoter to construct genetically engineered genes carrying heterologous codon-optimized ORFs and drive their expression under carbon-source regulation, we further expand the findings of Cormack et al. (1997) and Backen et al. (2000) that the CaMAL2 promoter, like the CaMET3 promoter (Care et al., 1999), can be used to generate C. albicans strains expressing different genes of interest and perform functional studies. In addition, our data support the conclusion of Backen et al. (2000) that the CaMAL2 promoter can provide an effective way for tightly regulating gene expression in C. albicans.

Together with previously reported data (Cormack et al., 1997; Morschhauser et al., 1998), our results indicate that expression of heterologous proteins in C. albicans may be greatly facilitated by employing codonoptimization strategies. Heterologous expression of histatin proteins in their natural target $C$. albicans should prove to be a useful tool for studying the mechanism by which these molecules exert their biological activity. Moreover, this approach presents us with a system that will allow dissection of the requirements of histatin binding from the subsequent intracellular events, thus expanding our experimental possibilities in studying the mechanism of histatin candidacidal activity. This system should also be suitable for exploration of the intracellular cytotoxic effects of other protein antimycotic agents. Further understanding of these mechanisms may provide a molecular basis for development of improved therapeutic anticandidal drugs.

\section{ACKNOWLEDGEMENTS}

We thank Dr Howard Kuramitsu and Dr Lois Hoyer for their critical reading of the manuscript and helpful scientific comments, and Dr Arvind Thakur for use of the luminometer.
This work was supported by United States Public Health grants DE10641-07 and DE00406 from the National Institute of Dental and Craniofacial Research (to M.E.).

\section{REFERENCES}

Ahmed, A., Sesti, F., Ilan, N., Shih, T. M., Sturley, S. L. \& Goldstein, S. A. N. (1999). A molecular target for viral killer toxin: TOK1 potassium channels. Cell 99, 283-291.

Backen, A. C., Broadbent, I. D., Fetherston, R. W., Rosamond, J. D. C., Schnell, N. F. \& Stark, M. J. (2000). Evaluation of the CaMAL2 promoter for regulated expression of genes in Candida albicans. Yeast 16, 1121-1129.

Beelman, C. A. \& Parker, R. (1995). Degradation of mRNA in eukaryotes. Cell 81, 179-183.

Brown, D. H. Jr, Slobodkin, I. V. \& Kumamoto, C. A. (1996). Stable transformation and regulated expression of an inducible reporter construct in Candida albicans using restriction enzyme-mediated integration. Mol Gen Genet 251, 75-80.

Care, R. S., Trevethick, J., Binley, K. M. \& Sudbery, P. E. (1999). The MET3: a new tool for Candida albicans molecular genetics. Mol Microbiol 34, 792-798.

Cormack, B. P., Bertram, G., Egerton, M., Gow, N. A. R., Falkow, S. \& Brown, A. J. P. (1997). Yeast-enhanced green fluorescent protein $(\mathrm{yEGFP})$ : a reporter of gene expression in Candida albicans. Microbiology 143, 303-311.

Edgerton, M., Koshlukova, S. E., Lo, T. E., Chrzan, B. G., Straubinger, R. M. \& Raj, P. A. (1998). Candidacidal activity of salivary histatins: identification of a histatin 5-binding protein on Candida albicans. J Biol Chem 273, 20438-20447.

Geber, A., Williamson, P. R., Rex, J. H., Sweeney, E. C. \& Bennett, J. E. (1992). Cloning and characterization of a Candida albicans maltase gene involved in sucrose utilization. J Bacteriol 174, 6992-6996.

Helmerhorst, E. J., Breeuwert, P., van't Hof, W. \& 8 other authors (1999). The cellular target of histatin 5 on Candida albicans is the energized mitochondrion. J Biol Chem 274, 7286-7291.

Holm, I. (1986). Codon usage and gene expression. Nucleic Acids Res 14, 3075-3087.

Kelly, R., Miller, S. M., Kurtz, M. B. \& Kirsch, D. R. (1987). Directed mutagenesis in Candida albicans: one-step gene disruption to isolate ura3 mutants. Mol Cell Biol 7, 199-207.

Koshlukova, S. E., Lloyd, T. L., Araujo, M. W. B. \& Edgerton, M. (1999). Salivary histatin 5 induces non-lytic release of ATP from Candida albicans leading to cell death. J Biol Chem 274, 18872-18879.

Koshlukova, S. E., Araujo, M. W. B., Baev, D. \& Edgerton, M. (2000). Released ATP is an extracellular cytotoxic mediator in salivary histatin 5-induced killing of Candida albicans. Infect Immun 68, 6848-6856.

Kurtz, M. B., Cortelyou, M. W. \& Kirsch, D. R. (1986). Integrative transformation of Candida albicans, using a cloned Candida albicans ADE2 gene. Mol Cell Biol 6, 142-149.

Lehrer, R. I., Ganz, T. \& Selsted, M. E. (1991). Defensins: endogenous antibiotic peptides of animal cells. Cell 64, 229-230.

Losberger, C. \& Ernst, J. F. (1989). Sequence of the Candida albicans gene encoding actin. Nucleic Acids Res 17, 9488.

Maneu, V., Cervera, A. M., Martinez, J. P. \& Gozalbo, D. (1996). Molecular cloning and characterization of a Candida albicans gene (EFB1) coding for the elongation factor EF-1 $\beta$. FEMS Microbiol Lett 145, 157-162.

Morschhauser, J., Michel, S. \& Hacker, J. (1998). Expression of 
chromosomally integrated, single-copy GFP gene in Candida albicans, and its use as a reporter of gene regulation. Mol Gen Genet 257, 412-420.

O'Connell, B. C., Xu, T., Walsh, T. J., Sein, T., Mastrangeli, A., Crystal, R. G., Oppenheim, F. G. \& Baum, B. J. (1996). Transfer of a gene encoding the anticandidal protein histatin 3 to salivary glands. Hum Gene Ther 7, 2255-2261.

Odds, F. C. (1988). Candida and Candidiosis, a Review and Bibliography, 2nd edn. London: Baillière Tindall.

Odds, F. C. (1994). Candida species and virulence. ASM News 60, 313-318.

Oppenheim, F. G., Yang, Y. C., Diamond, R. D., Hyslop, D., Offner, G. D. \& Troxler, R. F. (1986). The primary structure and functional characterization of the neutral histidine-rich polypeptide from human parotid secretion. J Biol Chem 261, 1177-1182.

Oppenheim, F. G., Xu, T., McMillian, F. M., Levitz, S. M., Diamond, R. D., Offner, G. D. \& Troxler, R. F. (1988). Histatins, a novel family of histidine-rich proteins in human parotid secretion. Isolation, characterization, primary structure and fungistatic effects on Candida albicans. J Biol Chem 263, 7472-7477.

Ross, J. (1995). mRNA stability in mammalian cells. Microbiol Rev 59, 423-450.

Sabatini, L. M., Carlock, L. R., Johnson, G. W. \& Azen, E. A. (1987). cDNA cloning and chromosomal localization (4q11-13) of a gene for statherin, a regulator of calcium in saliva. Am J Hum Genet 41, 1048-1060.

Sambrook, J., Fritsch, E. F. \& Maniatis, T. (1989). Molecular Cloning: a Laboratory Manual, 2nd edn., Cold Spring Harbor, NY: Cold Spring Harbor Laboratory.

Santos, M. A. \& Tuite, M. F. (1995). The CUG codon is decoded in vivo as serine and not leucine in Candida albicans. Nucleic Acids Res 23, 1481-1486.
Schaller, M., Schafer, W., Korting, H. C. \& Hube, B. (1998). Differential expression of secreted aspartyl proteinases in a model of human oral candidosis and patient samples from the oral cavity. Mol Microbiol 29, 605-615.

Swoboda, R. K., Broadbent, I. D., Bertram, J., Budge, S., Gooday, G., Gow, A. R. \& Brown, A. J. P. (1995). Structure and regulation of a Candida albicans RP10 gene which encodes an immunogenic protein homologous to Saccharomyces cerevisiae ribosomal protein 10. J Bacteriol 177, 1239-1246.

Te'o, V. S., Cziferszky, A. E., Bergquist, P. L. \& Nevalainen, H. K. M. (2000). Codon optimization of xylanase gene $x y n B$ from the thermophilic bacterium Dictyoglomus thermophilum for expression in the filamentous fungus Trichoderma reesei. FEMS Microbiol Lett 190, 13-19.

vanderSpek, J. C., Offner, G. D., Troxler, R. F. \& Oppenheim, F. G. (1990). Molecular cloning of human submandibular histatins. Arch Oral Biol 35, 137-143.

Wang, A. M., Doyle, M. V. \& Mark, D. F. (1989). Quantitation of mRNA by the polymerase chain reaction. Proc Natl Acad SciU S A 86, 9717-9721.

Xu, T., Levitz, S. M., Diamond, R. D. \& Oppenheim, F. G. (1991). Anticandidal activity of major human salivary histatins. Infect Immun 59, 2549-2554.

Xu, Y., Ambukar, I., Yamagishi, H., Swaim, W., Walsh, T. J. \& O'Connell, B. C. (1999). Histatin 3-mediated killing of Candida albicans: effect of extracellular salt concentration on binding and internalization. Antimicrob Agents Chemother 43, 2256-2262.

Yanisch-Perron, C., Vieira, J. \& Messing, J. (1985). Improved M13 phage cloning vectors and host strains: nucleotide sequences of the M13mp18 and pUC19 vectors. Gene 33, 103-119.

Received 1 May 2001; revised 6 August 2001; accepted 13 August 2001. 